\title{
Non-Study Device Issue
}

National Cancer Institute

\section{Source}

National Cancer Institute. Non-Study Device Issue. NCI Thesaurus. Code C112361.

Issue associated with any deviations from specifications relating to non-study device or equipment operations. 